\title{
BMJ Open Risk of high-grade lesions after atypical glandular cells in cervical screening: a population-based cohort study
}

\author{
Ingrid Norman,, ${ }^{1,2}$ Anders Hjerpe, ${ }^{1,2}$ Joakim Dillner ${ }^{1,2}$
}

To cite: Norman I, Hjerpe A, Dillner J. Risk of highgrade lesions after atypical glandular cells in cervical screening: a population-based cohort study. BMJ Open 2017;7:e017070. doi:10.1136/ bmjopen-2017-017070

- Prepublication history for this paper is available online. To view these files, please visit the journal online (http://dx.doi. org/10.1136/bmjopen-2016017070).

Received 31 March 2017 Revised 19 October 2017 Accepted 31 October 2017

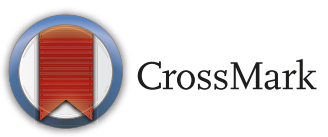

${ }^{1}$ Department of Clinical Pathology and Cytology, Karolinska University Laboratory, Karolinska University Hospital, Stockholm, Sweden

${ }^{2}$ Department of Laboratory Medicine, Karolinska Institutet, Stockholm, Sweden

Correspondence to Dr Ingrid Norman; ingrid.norman@ki.se

\section{ABSTRACT}

Objectives To determine how human papillomavirus (HPV) positivity of atypical glandular cells (AGCs) affects the predictive values for the presence of high-grade cervical lesions.

Design Population-based cohort study.

Setting Stockholm-Gotland region, Sweden.

Participants Between 17 February 2014 and 30 June

2016, there were 562 women with AGC detected in a

cervical sample. Registry linkages up to 30 June 2016

identified 392 women with an associated HPV test and a

histopathological follow-up.

Main outcome measure Presence of a high-grade cervical lesion in the cervical biopsy taken after the AGC smear, in relation to the HPV status of the AGC-containing index smear.

Results The proportion of HPV-positive AGC was $56 \%(n=222)$. In this group, there were six cases of invasive cervical adenocarcinoma, 33 cases of cervical adenocarcinoma in situ and 93 cases of high-grade squamous intraepithelial lesion (HSIL), giving a positive predictive value (PPV) for a cervical high-grade lesion of $60 \%$ (132/222). Among the 170 women with HPV-negative AGC, there was one invasive cervical squamous cell cancer and four HSIL, giving an PPV for a cervical highgrade lesion of $2.9 \%(5 / 170)$. This group also contained five endometrial cancers and one breast cancer.

Conclusions HPV triaging of AGC will greatly increase the predictive ability for identifying cervical high-grade lesions (OR: 48.4 (95\% Cl 19.1 to122.6)) and the high sensitivity (96\%; 132/137 women) implies safety of primary HPV screening strategies, with regard to this subset of patients. The measurable risk for endometrial cancer among women with HPV-negative AGC (2.9\%) suggests that research on screening for endometrial cancer is needed.

\section{BACKGROUND}

Organised cervical screening programme have resulted in a marked decline in the incidence of cervical squamous cell carcinomas (SCC). ${ }^{1}$ However, the effect on invasive cervical adenocarcinoma (ADCA $)^{1}$ has been much less. Several countries now report that $20 \%$ or more of all remaining invasive cervical carcinoma are $\mathrm{ADCA},{ }^{2}$ and some studies have even reported an increasing incidence of cervical ADCA. ${ }^{34}$ Whereas the precursor

\section{Strengths and limitations of this study}

- A large and population-based study, nested within an organised screening programme that mandated identical clinical follow-up for human papillomavirus (HPV)-positive and HPV-negative atypical glandular cell (AGC).

- The entire cohort was followed using comprehensive registries.

- Not all women with AGC had had an HPV test performed and not everyone had a histopathology follow-up.

- Cytological diagnosis of AGC may be variable between settings.

lesions of SCC and their management strategies are well recognised, the precursors of ADCA and their optimal management strategies are less clear. Cytological criteria for premalignant columnar cell lesions were recognised as late as in the mid-1990s. ${ }^{5}$ This increased the possibility to identify and treat such lesions. Women with a history of atypical glandular cell (AGC) have a greatly increased risk for later development of cervical cancer, probably because of persisting uncertainty regarding how to identify and manage these high-risk women. ${ }^{6}$

Most countries have switched from conventional to liquid-based cytology (LBC), which has made it easier to identify AGC. ${ }^{78}$ In Sweden, AGCs are reported in less than $0.3 \%$ of cervical samples. ${ }^{9}$ AGC not only signal an ADCA precursor lesion, they may also be caused by benign conditions such as cervical polyps, hyperplasia and tubar metaplasia. ${ }^{10}$ AGC is a high-risk marker for high-grade squamous intraepithelial lesion (HSIL), SCC ${ }^{11}$, adenocarcinoma in situ (AIS) or ADCA. ${ }^{12}$ AGC found at cervical screening is associated with a high and persistent risk of cervical cancer for up to 15 years, particularly for ADCA and among women aged 30-39 years. ${ }^{6}$ The current management of AGC thus does not seem to be optimally 
effective in preventing cervical cancer. ${ }^{6}$ Cervical cytology is primarily a screening test for squamous intraepithelial lesions and SCC. Sensitivity for glandular lesions is more variable due to sampling and interpretation issues, and because glandular lesions are less common, less well-defined and mav also include reactive conditions. ${ }^{13}$

Human papillomavirus (HPV) reflex testing on atypical squamous cells of undertermined significance (ASCUS) and low-grade squamous intraepithelial lesions (LSIL) is routinely used to increase predictive value HSIL and referral to colposcopy. ${ }^{14} \mathrm{~A}$ systematic review found 12 studies of HPV testing in glandular lesions and found that about $40 \%$ of AGC were high-risk positive and that predictive values were increased if AGC was triaged with HPV testing. ${ }^{15}$ However, HPV-negative AGC above 50 years of age may contain a substantial number of non-cervical cancers, ${ }^{15}$ and the value of HPV triage in the management of AGC is, therefore, not clear.

While cervical screening does not aim to detect endometrial carcinoma, occasionally, abnormal endometrial cells are detected in cervical samples and may lead to an earlier diagnosis of endometrial carcinoma. ${ }^{16}$ There are no guidelines or cost-effectiveness evaluations that consider a possible benefit of cervical screening on early diagnosis of endometrial carcinoma. Nevertheless, most guidelines recommend clinical follow-up of abnormal endometrial cells should they be found. ${ }^{16}$

As endometrial cancer and abnormal endometrial cells are negative for $\mathrm{HPV},{ }^{11}$ and as primary cervical screening with HPV is now a globally recommended practice, ${ }^{17}$ there is a concern that switching to HPV-based screening may result in losing a possible benefit of early diagnosis of endometrial cancer. The organised cervical screening programme of the Stockholm-Gotland region in Sweden decided on 17 February 2014 to introduce HPV triaging for all women with AGC, while retaining the same management guidelines for both HPV-positive and HPV-negative women with AGC.

The present study included all cases of AGC in the region during the period 17 February 2014 to 30 June 2016. We determined how HPV triaging of AGC affected the predictive values for subsequent diagnosis of high-grade cervical lesions and cancer or endometrial cancers.

\section{MATERIAL AND METHODS}

\section{Study population, data collection and analysis}

The Swedish cervical screening programme invites all women for screening every third year (23-49 years of age) or fifth year (50-64 years of age). ${ }^{18}$ Annually, nearly 800000 cervical samples are reported in Sweden and about 100000 samples were collected in the greater Stockholm County and Gotland region. About 75-80 000 samples per year are taken as a result of an invitation within the organised programme and about 20-25 000 samples are taken during follow-up or opportunistically. To minimise risk for selection biases in inclusion or follow-up, this population-based cohort study included all women who lived in the Stockholm-Gotland region of Sweden and had a primary cervical screening result from 17 February 2014 to 30 June 2016 (about 200000 women). A comprehensive screening registry where all samples in the region are registered was used to identify all of women who had an AGC diagnosis on their Pap test $(n=564)$, if there was a corresponding HPV test and if there was a subsequent histopathological diagnosis. HPV tests performed within 40 days before or after the AGC index sample (most HPV tests $378 / 392(96 \%)$ were performed within 5 days of the AGC diagnosis) were considered to likely reflect the HPV status of the index sample. In the organised programme, LBC samples were collected by midwives using plastic Ayre-like spatula and an endocervical brush (Medscand; Cooper Surgical Company, Berlin, Germany). The cervical cells were obtained from the ectocervix and endocervix of the uterus and suspended in PreservCyt, a methanol-based fixative medium, as recommended by the manufacturer (ThinPrep; Hologic, Marlborough, Massachusetts, USA). The cervical LBC samples were transferred to cytology glass slides using a ThinPrep 5000 processor (Hologic), and the remaining cell suspension was analysed for HPV DNA using the Cobas $4800 \mathrm{HPV}$ test, with robotic decapping of ThinPrep vials ( $p 480$; Roche Molecular Diagnostic, Pleasanton, California, USA). Qualitative detection of high-risk HPV DNA was obtained by amplification of HPV 16, 18, 31, 33, 35, 39, 45, 51, 52, 56, 58, 59, 66 and 68 (with HPV 16 and HPV 18 in separate channels, the remaining high-risk types were reported as a group).

LBC samples were prepared and evaluated at the Department of Clinical Pathology and Cytology, Karolinska University Hospital, Sweden. A modification of the Bethesda system was used for cytological diagnostics including the diagnostic system for AGC but without further subgrouping within the AGC diagnosis. ${ }^{19}$ The Systematized Nomenclature of Medicine system was used for cytological and histological classification coding. ${ }^{20}$ When several histopathological diagnoses were given, the most severe histological diagnosis was taken as outcome. All 564 women were followed up for histopathologies, using registry linkages, until 30 June 2016. ORs and CIs were calculated using conditional logistic regression using EpiInfo (www.cdc.gov). Individual level data will be shared on request and to be sent to JD.

\section{Patient involvement}

No patient was involved in setting the research question or the outcome measures. The participants were not involved in developing plans for recruitment, design or implementation of the study. No patients were asked to advise on interpretation or writing up of results. There are no plans to disseminate the results of the research to study participants or the relevant patient community. Women were informed about their HPV and cytology results. 


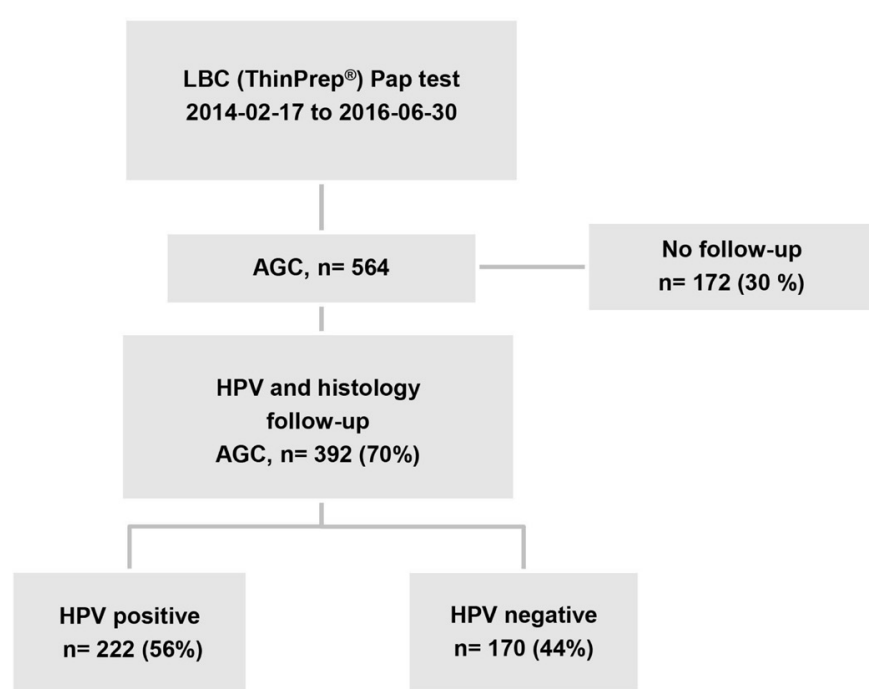

Figure 1 The study flow chart. AGC, atypical glandular cells; HR-HPV, high-risk human papillomavirus; LBC, liquid-based cytology; Pap, papanicolaou.

\section{Ethics}

In Sweden, the ethical review boards (ERBs) are appointed by government, chaired by a senior judge and have the authority to decide on the requirements for consent. For this study, the ERB decided that consent was not required and all women resident in the population of the Stockholm/Gotland region could be included in the study.

\section{RESULTS}

During 17 February 2014 to 30 June 2016, altogether 564 primary cervical cytology samples (ThinPrep, Hologic) were diagnosed as AGC. A total of 172 samples were excluded in the study. Of these, $76(13 \%)$ samples had no associated HPV test and $96(17 \%)$ samples had no histological follow-up. In total, there were $392(70 \%)$ women who had had an associated HPV test and a subsequent histopathological follow-up. The mean age of these women was 38 years (range 23-86 years) (figure 1).
The risk of being HR-HPV positive decreased with increasing age: $62 \%, 60 \%$ and $25 \%$ of samples were HPV positive among women $<40$ years, $40-50$ years, and $\geq 50$ years respectively (table 1 ).

Among the HPV-positive AGC, the subsequent histologies identified $6(3 \%)$ cases of cervical ADCA, 33 (15\%) cases of AIS and 93 (42\%) cases of HSIL. The PPV for a high-grade lesion was 132/222 (60\%). The corresponding figures for the HPV-negative AGC group was five endometrial cancers, one cervical SCC and four HSIL, giving a PPV of 5/170 (3\%) for cervical high-grade lesions and $3 \%$ for endometrial cancer. HR-HPV was thus found in 132/137 cases (sensitivity $96 \%$ ) with cervical high-grade lesions to treat (OR: 48.4 (95\% CI 19.1 to 122.6)) but in none of the five endometrial cancers (figure 2).

In the HPV-positive group of 165 women younger than age 40,71 cases $(41 \%)$ had HSIL, 26 cases $(16 \%)$ had AIS and 5 cases (3\%) were cervical ADCA. Among the $45 \mathrm{HPV}$-positive women between the ages of 40 and 50 , 20 cases $(44 \%)$ were HSIL, 6 cases $(13 \%)$ were AIS and 1 case $(2 \%)$ was cervical ADCA. Among the 12 women older than 50 years of age, there were two $(16 \%)$ HSIL cases and one $(8 \%)$ AIS case.

All 5 endometrial ADCA were found among the 36 HPV-negative women $>50$ years of age (PPV: 14\%) (table 2).

\section{DISCUSSION}

\section{Statement of main findings}

The high predictive values for cervical lesions to treat an HPV-positive AGC indicates that ambitious clinical management algorithms that minimise risk the for loss to follow-up would need to be followed.

The sensitivity of HPV positivity for cervical high-grade lesions suggest that HPV-based screening strategies are safe with regards to finding AGC-associated cervical cancer precursor lesions.

The fact that all endometrial cancers were HPV negative suggest that further research is warranted on the

Table 1 Histological follow-up after HPV-positive or HPV-negative AGC, by age

\begin{tabular}{|c|c|c|c|c|c|c|c|c|}
\hline & \multicolumn{2}{|c|}{$<40$ years old } & \multicolumn{2}{|c|}{$40-50$ years old } & \multicolumn{2}{|c|}{$>50$ years old } & \multicolumn{2}{|l|}{ Total } \\
\hline & HPV+ & HPV- & HPV+ & HPV- & HPV+ & HPV_- & HPV+ & HPV- \\
\hline WNL & 38 & 50 & 12 & 55 & 6 & 22 & 56 & 127 \\
\hline LSIL & 25 & 12 & 6 & 13 & 3 & 7 & 34 & 32 \\
\hline HSIL & 71 & 1 & 20 & 2 & 2 & 1 & 93 & 4 \\
\hline SCC & 0 & 0 & 0 & 0 & 0 & 1 & 0 & 1 \\
\hline AIS & 26 & 0 & 6 & 0 & 1 & 0 & 33 & 0 \\
\hline ADCA cx & 5 & 0 & 1 & 0 & 0 & 0 & 6 & 0 \\
\hline Total & 165 & 63 & 45 & 70 & 12 & 31 & 222 & 164 \\
\hline PPV & $62 \%$ & $1.6 \%$ & $60 \%$ & $2.8 \%$ & $25 \%$ & $6 \%$ & $60 \%$ & $3 \%$ \\
\hline
\end{tabular}

ADCA cx, adenocarcinoma cervix; AGC, atypical glandular cell; AIS, endocervical adenocarcinoma in situ; HPV, human papillomavirus; HSIL, high-grade intraepithelial lesion; LSIL, low-grade intraepithelial lesion; PPV, positive predictive value; SCC, squamous cervical cancer; WNL, within normal limits. 


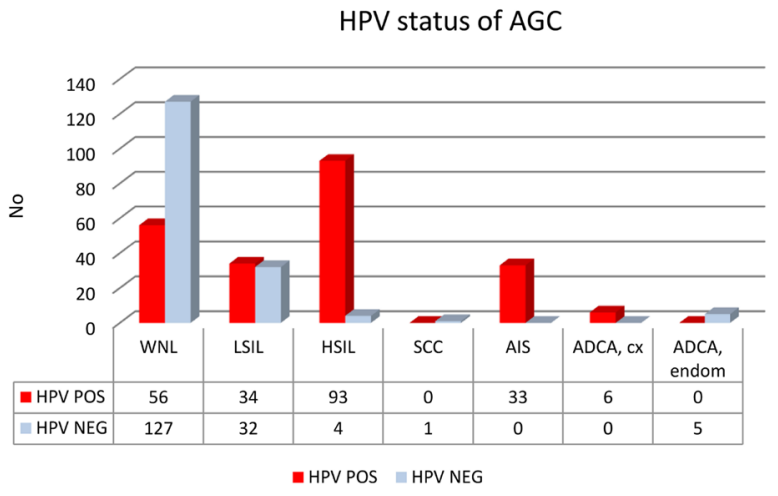

Figure 2 Histological findings in HPV-positive and HPVnegative AGC cases. Advanced cervical lesions were found in $60 \%$ of HPV-positive AGC cases while only in $3 \%$ of the HPV-negative ones, corresponding to a sensitivity of $96 \%$ (132/137). ADCA cX, cervical adenocarcinoma; ADCA endom, endometrial adenocarcinoma; AGC, atypical glandular cell; AIS, adenocarcinoma in situ (cervical); HPV, human papillomavirus; HSIL, high-grade intraepithelial lesion; LSIL, low-grade intraepithelial lesion; SCC, squamous cell carcinoma (cervical); WNL, within normal limits.

possible benefit of cervical cytological screening on early diagnosis of endometrial cancer.

\section{Strengths of study}

The present study is large and population based, nested within an organised screening programme that mandated identical clinical follow-up for HPV-positive AGC and HPV-negative AGC. The entire cohort was followed using comprehensive registries and the risk for ascertainment bias in follow-up is thus minimal. The setting also implies high generalisability.

\begin{tabular}{|c|c|c|c|c|c|}
\hline & \multicolumn{3}{|c|}{ Age (years) } & \multirow[b]{2}{*}{ Total } & \multirow[b]{2}{*}{$\%$} \\
\hline & $<40$ & $40-50$ & $>50$ & & \\
\hline WNL & 88 & 67 & 28 & 183 & 46.3 \\
\hline LSIL & 37 & 19 & 10 & 66 & 16.8 \\
\hline HSIL & 72 & 22 & 3 & 97 & 25.4 \\
\hline SCC & 0 & 0 & 1 & 0 & 0.3 \\
\hline AIS & 26 & 6 & 1 & 33 & 8.1 \\
\hline ADCA, Cx & 5 & 0 & 1 & 6 & 1.5 \\
\hline ADCA, endom & 0 & 0 & 5 & 5 & 1.3 \\
\hline ADCA met & 0 & 0 & 1 & 1 & 0.3 \\
\hline Total & 228 & 114 & 50 & 392 & \\
\hline PPV & $45 \%$ & $25 \%$ & $12 \%$ & & \\
\hline
\end{tabular}

ADCA cx, adenocarcinoma cervix; ADCA

endom, adenocarcinoma endometrial; ADCA

met, adenocarcinoma metastasis; AGC, atypical glandular cell; AIS, endocervical adenocarcinoma in situ; HSIL, highgrade intraepithelial lesion; LSIL, low-grade intraepithelial lesion; PPV, positive predictive value; SCC, squamous cervical cancer; WNL, within normal limits.

\section{Limitations of study}

Not all women with AGC had had an HPV test performed (only $87 \%$ ). About $70 \%$ of cervical samples in the region are taken following an invitation with an appointment in the organised programme-the remainder are taken in other settings, for example, during clinical follow-up of cytological abnormalities detected in the screening programme. Whereas it is straightforward to ensure adherence to policies for samples taken in the organised programme, it is more complicated for samples taken in other settings and we consider an $87 \%$ compliance with the HPV triaging policy as high compliance.

A substantial proportion of women (17\%) had no histological follow-up. A nationwide audit found that one-third of women with AGC lacked histological follow-up. ${ }^{6}$ As this lack of follow-up was associated with very high risks for cancer, ${ }^{6}$ there is now a greatly increased awareness of the need for histological follow-up after AGC. For women with an index AGC close to the end of the study, lack of follow-up may simply reflect insufficient follow-up time in our study. However, late histopathologies not recorded in the study are not likely to be biased in relation to the outcomes of the study.

AGC is not an easily recognised entity and there may be differences in diagnostic practices between different laboratories. As the organised screening programme of region Stockholm-Gotland uses a single laboratory (Karolinska University Laboratory), the laboratory of the present study can be characterised as a high-volume, highly specialised laboratory. Thus, it is not certain that the predictive values found in this study can be generalised to other settings.

\section{Strengths and weaknesses in relation to other studies, discussing important differences in results}

The systematic review of Verdoodt $e t a l^{15}$ identified that there were only 12 studies on HPV in AGC and reported that, on average, $40 \%$ of AGC were HPV positive. We find a somewhat higher figure $(56 \% \quad(n=222)$ of AGC were HPV positive), which may be related to the fact that the screening programme uses a single, specialised laboratory. As far as we have could determine, ours is the largest population-based cohort study that has included subsequent histopathological diagnoses after AGC in relation to the HPV status of the index cytology.

The major previous study that reported on the HPV status of endometrial cancers detected after AGC found that all of them were HPV negative, ${ }^{11}$ which is in accordance with our results.

\section{Meaning of the study and implications for clinicians and policy-makers}

The very high predictive values of an HPV-positive AGC indicate that current clinical management algorithms may need to be revised to minimise the risk that existing lesions escape detection and most importantly to minimise the risk that women will be lost to follow-up. 
The high sensitivity of HPV positivity for cervical high-grade lesions among AGC suggests that the switch to HPV-based screening is safe with regards to catching AGC-associated cervical cancer precursor lesions. Only $3 \%$ of the HSIL lesions detected after AGC would be missed by not referring HPV-negative AGC, although this percentage may not reflect HPV-negative lesions in screening tests as a whole. Some programmes are contemplating the use of double testing with both HPV and cytology at least once per lifetime, and this would enable detection of this small subset of HSIL that occurs after HPV-negative AGC along with others without AGC.

Although the sensitivity is not $100 \%$, the greatly increased PPV for the HPV-positive women with AGC that are referred implies that only HPV-positive AGC need to be referred. If more stringent management algorithms are used for these women, this may increase safety although fewer women will be referred. This phenomenon has been demonstrated in our randomised implementation of HPV triaging of ASCUS/LSIL samples, where the arm referring only to HPV-positive ASCUS/LSIL found more high-grade lesions despite referring fewer women. ${ }^{21}$

\section{Unanswered questions and future research}

The HPV negativity of endometrial cancers is in accordance with other studies ${ }^{11}$ and indicates that with the ongoing switch to HPV-based screening, there will be no benefit of early diagnosis of endometrial cancers. It is not entirely clear if endometrial cancer detected early through cervical screening ever resulted in a measurable health benefit. ${ }^{22}$ Further research to establish whether this was indeed the case seems warranted.

With the switch to HPV-based cervical screening, there will no longer be any early detection of endometrial cancers and further studies to elucidate whether this should be remedied are warranted.

The new screening modality will detect only HPV-positive AGC. This will result in a greatly increased PPV compared with AGG with unknown HPV status, and with HPV-based screening the management guidelines for AGC would need to be substantially changed to reflect this. Recent guidelines in France recommend HPV triaging of AGC, ${ }^{22}$ a strategy supported by our results.

Acknowledgements We thank the colleagues at the Regional Cancer Center of Stockholm/Gotland, in particular, Agneta Carlsten Thor for their help and support.

Contributors IN: Retrieved and evaluated data, is guarantor of the study and coordinated the study design. AH: Provided supervision. JD: Provided supervision and resources. All authors revised the manuscript for important intellectual content and have approved the final version for submission.

Funding This study was funded by Stockholm County Clinical Research funds. Competing interests None declared.

Ethics approval The study was approved by the regional ethical board of Stockholm (decision no: 2016/1103-31).

Provenance and peer review Not commissioned; externally peer reviewed.

Data sharing statement Individual level data are available from the corresponding author.
Open Access This is an Open Access article distributed in accordance with the Creative Commons Attribution Non Commercial (CC BY-NC 4.0) license, which permits others to distribute, remix, adapt, build upon this work non-commercially, and license their derivative works on different terms, provided the original work is properly cited and the use is non-commercial. See: http://creativecommons.org/ licenses/by-nc/4.0/

(c) Article author(s) (or their employer(s) unless otherwise stated in the text of the article) 2017. All rights reserved. No commercial use is permitted unless otherwise expressly granted.

\section{REFERENCES}

1. Sherman ME, Wang SS, Carreon J, et al. Mortality trends for cervical squamous and adenocarcinoma in the United States. Relation to incidence and survival. Cancer 2005;103:1258-64.

2. Sarian LO, Rabelo-Santos SH, Derchain SFM, et al. Diagnostic and therapeutic challenges in the management of glandular abnormalities of the cervix. Expert Rev Obstet Gynecol 2012;7:49-58.

3. Hemminki K, Li X, Mutanen P. Age-incidence relationships and time trends in cervical cancer in Sweden. Eur J Epidemiol 2001;17:323-8.

4. Smith HO, Tiffany MF, Qualls CR, et al. The rising incidence of adenocarcinoma relative to squamous cell carcinoma of the uterine cervix in the United States: a 24-year population-based study. Gynecol Oncol 2000;78:97-105.

5. van Aspert-van Erp AJ, van 't Hof-Grootenboer AB, Brugal G, et al. Endocervical columnar cell intraepithelial neoplasia. I. Discriminating cytomorphologic criteria. Acta Cytol 1995;39:1199-215.

6. Wang J, Andrae B, Sundström K, et al. Risk of invasive cervical cancer after atypical glandular cells in cervical screening: nationwide cohort study. BMJ 2016;352:i276.

7. Diaz-Montes TP, Farinola MA, Zahurak ML, et al. Clinical utility of atypical glandular cells (AGC) classification: cytohistologic comparison and relationship to HPV results. Gynecol Oncol 2007;104:366-71.

8. Ashfaq R, Gibbons D, Vela C, et al. Accuracy for glandular disease. Acta cytologica 1999;43:81-5.

9. NKCx, NKfC. Nationella årsrapporten om cellprovtagning i Sverige under 2015, 2015.

10. Sharpless KE, Schnatz PF, Mandavilli S, et al. Dysplasia associated with atypical glandular cells on cervical cytology. Obstet Gynecol 2005;105:494-500.

11. Castle PE, Fetterman B, Poitras N, et al. Relationship of atypical glandular cell cytology, age, and human papillomavirus detection to cervical and endometrial cancer risks. Obstet Gynecol 2010;115:243-8.

12. Schnatz PF, Guile M, O'Sullivan DM, et al. Clinical significance of atypical glandular cells on cervical cytology. Obstet Gynecol 2006;107:701-8.

13. Moriarty AT, Wilbur D. Those gland problems in cervical cytology: faith or fact? Observations from the Bethesda 2001 terminology conference. Diagn Cytopathol 2003;28:171-4.

14. Ronco G, Giorgi-Rossi P, Carozzi F, et al. Efficacy of human papillomavirus testing for the detection of invasive cervical cancers and cervical intraepithelial neoplasia: a randomised controlled trial. Lancet Oncol 2010;11:249-57.

15. Verdoodt F, Jiang X, Williams M, et al. High-risk HPV testing in the management of atypical glandular cells: a systematic review and meta-analysis. Int J Cancer 2016;138:303-10.

16. Arbyn MAA, Jordan J. European guidelines for quality assurance in cervical cancer screening. 2nd edn. Luxembourg: Office for Official Publications of the European Communities, 2008:1-291.

17. Arbyn M, Anttila A, Jordan J, et al. European guidelines for quality assurance in cervical cancer screening. second edition--summary document. Ann Oncol 2010;21:448-58.

18. Andrae B, Andersson TM, Lambert PC, et al. Screening and cervical cancer cure: population based cohort study. BMJ 2012;344:e900.

19. Nayar RW, Wilbur D. The Bethesta system for reporting cervical cytology. 3rd edn. Switzerland: Springer International Publishing, 2015.

20. Patologi SFfKCoSFfK. Cervixcytologi. KVAST-Exfoliativ cytologi, 2017.

21. Dillner L, Kemetli L, Elfgren K, et al. Randomized health services study of human papillomavirus-based management of low-grade cytological abnormalities. Int J Cancer 2011;129:151-9.

22. Conduite à tenir devant une femme ayant une cytologie cervicoutérine anormale/ Recommandations et référentiels. Cancers gynécologiques. 2016 www.e-cancer.fr. 